\title{
Um Olhar Sobre a Influência do Oriente em Encenadores Ocidentais do Século XX
}

\section{* Ariane Guerra Barros}

\section{Resumo}

O presente artigo busca indicar influências orientais em alguns encenadores ocidentais do século XX, fazendo um levantamento de algumas características ditas orientais em métodos de atuação e encenação, sob o ponto de vista corporal. Conceituando primeiramente a denominação "Oriente", procuro realizar uma abordagem com vistas a sinalizar pensamentos, técnicas e métodos orientais e sua influência em encenadores ocidentais, sendo estes: Constantin Stanislavski, Edward Gordon Craig, Bertolt Brecht, Antonin Artaud, Jerzy Grotowski, Eugenio Barba e Luís Otávio Burnier.

Palavras-chave: teatro-oriente - ocidente

\begin{abstract}
This article seeks to indicate the Eastern influence in some Western directors of the twentieth century in order to identify those characteristics in eastern methods of acting and staging, under the body point of view. First conceptualizing the "Eastern" denomination, I try to make an approach in order to signal thoughts, techniques and Eastern methods and its influence on Western directors, namely: Konstantin Stanislavsky, Edward Gordon Craig, Bertolt Brecht, Antonin Artaud, Jerzy Grotowski, Eugenio Barba and Luis Otavio Burnier.
\end{abstract}

keywords: theater-eastern - western

\footnotetext{
* Professora do curso de Artes Cênicas na Universidade Federal da Grande Dourados (UFGD), Mestre em Artes Cênicas pelo Programa de Pós-graduação em Ârtes Cênicas da Universidade Federal do Rio Grande do Sul.

E-mail: ariane.guerra@gmail.com
} 
A expressão corporal ocidental, [...] utiliza-se, nos exercicios preparatórios, de princípios ligados à medicina chinesa e às artes marciais mais que à ginástica ocidental. Pode-se mesmo afirmar que quase todas as grandes inovações do trabalho corporal contemporâneo têm suas bases no Oriente, ou identificam-se de algum modo com os principios orientais (AZEVEDO, 2004, p. 286).

Baseada em Sônia Machado de Azevedo (de acordo com citação acima), já em 2004, podemos perceber a influência que o oriente tinha em técnicas e treinamentos ocidentais, sob o ponto de vista corporal. Este encantamento pelo oriente acabou por se tornar uma espécie de vanguarda, um 'ismo' na história do teatro: o chamado "orientalismo", de acordo com Grande Rosales (1998-2001). Compreendendo esse fenômeno como a fascinação dos criadores teatrais ocidentais pela cultura e tradições orientais, entendo que entre estes espaços geográficos as fronteiras encontram-se, de certo modo, 'borradas'. Desta forma, é possível entender que não existe apenas um oriente ou ocidente, mas, de certa forma, orientes e ocidentes espalhados pelo mundo, sem localização territorial limitada. Assim, considero como "oriental" ou "Oriente" a forma de pensamento e técnicas que alguns povos orientais - de países como Índia, China e Japão - trazem em sua cultura, em suas artes, em seu modo de agir, entendido como uma fonte de cultura que engloba filosofias, ideologias, idiossincrasias, valores e princípios próprios e peculiares relacionados diretamente com a complexidade asiática, não se limitando à sua área geográfica (GUERRA, 2015).

Uma das principais características observadas pelos encenadores ocidentais do século XX, ao lançar seu olhar para o Oriente, foi a utilização de uma técnica precisa como codificação teatral. Segundo Barba, o ator oriental "Possui uma base orgânica e bem testada de 'conselho absoluto'; isto é, regras de arte que codificam um estilo de representação fechado ao qual todos os atores de um determinado gênero devem adequarse" (1995, p. 8). Em certas vertentes cênicas no oriente, é também regra que o ator de determinado estilo não assista nem entre em contato com outras técnicas de representação, a fim de não 'poluir-se' com elas. Assim, temos uma via de duplo sentido, em que a dedicação a uma determinada técnica faz com que o ator aprofunde seu domínio corporal e, ao mesmo tempo, porém, limite-se a ela. Segundo Azevedo,

No treinamento do ator oriental não existe a expressão corporal no sentido em que a conhecemos no Ocidente, o que ocorre é o aprendizado exato e detalhado do gestual que deverá fazer parte do repertório do artista, sua repetição sistemática, sua memorização absoluta (2004, p. 132).

A codificação e simbolização de gestos e movimentos são passadas de geração a geração, e trazem em si a questão da espiritualidade, trabalhada por meio de um treinamento de longa duração e visando à disciplina e a aprendizagem do ator. Para o artista oriental, o sentimento não pode ser imitado, apenas sugerido, da mesma forma que as transformações de cenário e outros maquinismos não são escondidos. Cada gesto ou movimento tem um significado preciso no teatro oriental, e seus aspectos simbólicos correspondentes são compreendidos e aceitos pelo público (GUERRA, 2015).

Outro aspecto oriental que encantava os encenadores ocidentais era o conceito "holístico" e multidisciplinar do ator. O ator oriental deveria desenvolver múltiplas competências, competências estas, entendidas, no ocidente, como a serem desenvolvidas por profissionais diferentes. O ator oriental seria, ao mesmo tempo: dançarino, cantor, músico, e artista marcial. Trata-se daquilo que Azevedo chama de "intérprete completo" (2004, p. 132), e Yoshi Oida conceitua como 'teatro total', em que "A somatória dessas habilidades é o que os ocidentais deveriam chamar de “interpretação”' (2007, p. 13).

Não podemos deixar de lado uma das maiores influências orientais, que gerou raízes e aprofundamentos em diversos âmbitos, desde práticos até acadêmicos: o aspecto energético do ator. Enquanto o ator oriental trabalhava a energia de forma 'direta', o ator ocidental buscava fundamento em ações e emoções internas. Exemplifico da seguinte forma: o ator ocidental caminha para algum lugar (no palco) de acordo com uma determinada causa ou objetivo, enquanto o ator oriental encontra-se num modus operandi ininterrupto, num caminhar contínuo. Entendo como diferença entre o ator ocidental e o oriental o tempo dos verbos: enquanto o ator ocidental utiliza o verbo (ação, neste caso) no tempo infinitivo - caminhar, o ator oriental conjuga a ação no gerúndio, agindo - caminhando: podemos dizer que um preocupa-se com a meta, outro com a ação em si. Segundo Grotowski, os ocidentais improvisam as ações, os orientais improvisam as 'energias' (1992-1993b).

Porém, a questão que considero fundamental no teatro oriental, e que, certamente, alguns encenadores ocidentais trouxeram para si, se encontra na indissociabilidade entre corpo e espírito, vista no quesito holístico 
do ator oriental. É perceptível, na obra de diversos autores ocidentais (cito como exemplos Antonin Artaud, Jerzy Grotowski, Richard Schechner, Eugenio Barba e Peter Brook, entre outros), a predominância da dualidade corpo-mente. Através do diálogo intercultural, o foco do teatro, no entanto, modificou-se: Artaud formula seu Teatro da Crueldade depois de assistir uma apresentação de teatro balinesa; Grotowski busca no teatro indiano exercícios para seus atores; e Schechner procura nos escritos sobre o teatro Nô a fundamentação para os estudos da performance. Essa abordagem corporal em que o "estado mental” vai além do intelecto e da razão é a base para que se forme o novo ator no ocidente, o ator dito contemporâneo (FERNANDES, 2008).

Constantin Stanislavski utiliza princípios da cultura oriental no treinamento de seus atores, pois uma de suas premissas é a inseparabilidade entre corpo e alma, e nisso baseia seu método de preparação dos atores, pois "Todo o ato físico, exceto os puramente mecânicos, tem uma fonte interior de sentimento" (2005, p. 183). O método proposto pelo encenador busca a união entre sentimento e ação física. Segundo ele, "Usamos a técnica consciente de criar o corpo físico de um papel e, com seu auxílio, alcançamos a criação da vida subconsciente do espírito do papel" (2005, p. 185). Trata-se, pois, de um método de treinamento que se vale de uma abordagem psicotécnica consciente para se chegar ao subconsciente.

Stanislavski utiliza, através da cultura hindu, o prana, a energia vital. Para os hindus, o centro de irradiação desta energia concentra-se no plexo solar, um dos centros de gravidade corporal. Unindo o cérebro e o plexo e tentando estabelecer uma comunicação entre eles, o encenador russo descobriu o que seria a base de seu método: "A sensação era a de que meu cérebro mantinha intercâmbio com meus sentimentos. Fiquei encantado, pois encontrara o sujeito e o objeto que buscava (2005, p. 240).

Edward Gordon Craig homenageia, em sua revista The Mask, o teatro oriental (GRANDE ROSALES, 1998-2001). Craig mantinha contato com o orientalista Ananda K. Coomaraswamy (1877-1947), metafísico e filósofo, pioneiro na descoberta da história e filosofia da Arte Indiana e profundo conhecedor da cultura da Índia (QUILICI, 2001). Craig era contrário aos espetáculos em que atores e diretores europeus imitavam modalidades do teatro chinês e japonês, pois entendia tais imitações como superficiais. O cenógrafo defendia que essas representações eram 'aproximativas' e não se igualariam, em nenhuma hipótese, aos espetáculos tradicionalmente orientais (GRANDE ROSALES, 1998-2001). O teatro hindu parecia corresponder diretamente ao modelo que o autor pretendia: técnica exigente, código focalizando a expressão e espiritualidade (RAPOSO, 1997).

Outro encenador e pensador ocidental que se utiliza se algumas características e técnicas orientais em seus estudos e métodos é Bertolt Brecht. Podemos destacar, principalmente nele, o encontro com o ator oriental Mei Lang Fan (encontro que também se deu com Stanislavski e Meyerhold, ambos também conheceram Mei Lang Fan), em Moscou, no ano de 1935. Fan é tido como uma das referências para a reflexão de Brecht sobre o chamado "distanciamento" que posteriormente propõe a partir do texto intitulado O Efeito de Distanciamento nos Atores Chineses (BRECHT, 1967, p. 104-14). Para o teórico, a forma de representação ocidental buscava criar uma ilusão para o espectador, e o fato de o teatro tradicional chinês propor justamente o oposto foi o que inspirou Brecht em sua concepção acerca do distanciamento: de acordo com ele, trata-se de uma característica comum do teatro chinês, onde os atores nunca representavam como se houvesse uma quarta parede (GUERRA, 2015). A partir daí, Brecht entende que o ator deveria 'incorporar' tanto o personagem quanto, em certa medida, mostrar ao público sua própria personalidade. Influências orientais também são notadas nos textos de Brecht: a ópera Turandot (1953), por exemplo, é ambientada no palácio do imperador chinês, além de o dramaturgo utilizar, na caracterização dos personagens, máscaras orientais, nomes chineses e argumentos que remetiam à china imperial. Em Aquele que diz sim, aquele que diz não, de 1929, o cenário e os trajes dos personagens remetem diretamente ao quadro estético dos países comunistas orientais (GASPAR VERDÚ, 2003).

Já Antonin Artaud tem inspiração no teatro balinês. Exercícios de respiração orientais eram frequentemente usados pelo teórico como treinamento de seus atores, que esquadrinhavam a suposta "musculatura afetiva": para cada emoção, um movimento ou gesto correspondente (ARTAUD, 1999). Artaud tentava construir uma nova linguagem física, baseada em signos - como no teatro de Bali - e não mais nas palavras. Para cada circunstância havia um signo equivalente, concepção a partir da qual os gestos e mímicas de atores balineses transformavam-se em uma espécie de "arquitetura espiritual” (ARTAUD, 1999). A ideia de codificar o teatro com gestos e signos determinados devolveria à convenção teatral seu valor superior, como Artaud entendia pelo teatro balinês: "Tudo nesse teatro é calculado com uma minúcia adorável e matemática. Nada é deixado ao acaso ou à iniciativa pessoal. É uma espécie de dança superior, na qual os dançarinos seriam antes de tudo atores" (ARTAUD, 1999, p. 60). 
Jerzy Grotowski considera que o ator, para estar em cena, deve realizar uma autopenetração, uma revelação, um autoconhecimento. A chave para este processo seria a humildade (lembro que aqui estamos em busca de um "teatro pobre" (1987), onde iluminação, cenário e figurinos ficam em segundo plano, e o ator seria o principal elemento teatral) e a busca por um 'estado de transe', só alcançável pelo ator através de uma disciplina de entrega total ao ato teatral. O transe e a autorevelação são, segundo Grotowski, "[...] um extremo confronto, sincero, disciplinado, preciso e total - não apenas um confronto com seus pensamentos, mas um encontro que envolve todo o seu ser, desde os seus instintos e seu inconsciente até o seu estado mais lúcido” (1987, p. 41). Para Grotowski, o ator deve dominar um método, adotando os seguintes passos: 1) Estimular um processo de autorevelação; 2) Articular esse processo, disciplinando-o e convertendo-o em gestos (codificação); 3) Eliminar do processo criativo as resistências e os obstáculos causados pelo organismo de cada um, tanto físico como psíquico - a denominada via negativa de Grotowski (1987). O preparo e a condição física eram pontos fundamentais para o encenador, que se utilizava de exercícios de respiração praticados no teatro clássico chinês e a ioga como parte do preparo corporal e vocal dos atores.

Eugenio Barba investiga, em sua teoria e prática, aspectos orientais, utilizando conceitos, princípios e ideias orientais, além de buscar em atores orientais auxílio para sua práxis. É também em Barba que temos hoje amplo material teórico sobre o teatro oriental.

Barba recorre a uma grande variedade de expressões e denominações orientais em seus escritos. Buscando em diferentes partes do oriente técnicas que pudessem auxiliar o ator em seu treinamento, Barba desenvolve, a partir da dança indiana e das posições da ioga, exercícios que tragam a pré-expressividade à tona no corpo do ator (GUERRA, 2015). A palavra “extracotidiano" (BARBA, 1995), tão utilizada por Barba, é a junção de dois termos indianos: lokadharmi (comportamento da vida cotidiana) e natyadharmi (comportamento da dança), apresentados a ele pela dançarina indiana Sanjukta Panigrahi.

O significado do termo "extracotidiano" consiste, de acordo com o autor, na exploração de uma energia diferente da que o ator utiliza em sua vida diária. Algo que vai além das ações corriqueiras, já que, ainda segundo Barba, em nosso dia-a-dia, utilizamos um mínimo de esforço e energia para a ação; porém, nas práticas do teatro proposto pelo pesquisador, procura-se mobilizar uma energia além da habitual, consequência de um maior esforço (BARBA, 1995).

O termo energia tem vários correspondentes nas línguas orientais, como o japonês: ki-ai, kikoro, io-in, koshi, yugen; o balinês: taksu, virasa, bayu, chikara; e o chinês: shun toeng, tant’ien, ki e kung fu; além das palavras sânscritas indianas que têm quase o mesmo significado: prana e shakti. Já a raiz grega da palavra energia associa seu significado à ideia de ‘trabalho', e também às ideias de 'fluxo' e ‘vibração'. A energia, segundo Barba, é consequência e resultado de forças opostas que atuam no corpo do ator, gerando uma tensão. Barba denomina de dilatação essa força da energia atuando no corpo do ator, pois, para ele, não se trabalha no corpo ou na voz, mas diretamente na energia. Este estado corporal consiste em três elementos: 1) alteração do equilíbrio para o equilíbrio precário ou de luxo; 2) oposição, ou vetores opostos no corpo; 3) uso de uma incoerência coerente (BARBA, 1995). Essa tensão, ou força, não significa necessariamente movimento, existindo também na imobilidade. Trata-se, de acordo com Barba, de uma "imobilidade dinâmica" (1995). Esta força, este poder, é o que os atores determinam como presença. Essa força, essa presença, também traz algo de íntimo, de imobilidade e silêncio, e não apenas de excesso: é a potência em si (BARBA, 1995).

Outros termos de origem oriental e fundamentais no trabalho de Barba são: o termo japonês jo-ha-kyu, que serve para descrever as fases para as quais as ações de um ator convergem (Jo significa reter; ha, romper, libertar-se da força retida; e kyu, velocidade, onde a ação culmina). Jo-ha-kyu está presente não apenas nas ações, mas também na respiração, na música, em cada cena e peça: "É uma espécie de código que corre através de todos os níveis de organização do teatro” (BARBA, 1995, p. 18). No Japão, ao final de uma apresentação os espectadores usam uma expressão, otsukaresana, para agradecer aos atores. A expressão significa, literalmente, "você está cansado". Aos atores que não economizaram sua energia, os espectadores agradecem. Estas são apenas algumas das expressões orientais utilizadas por Barba em seu treinamento.

Em Luís Otávio Burnier (discípulo de Barba), podemos notar a influência oriental nas designações de algumas técnicas, vinculadas ao método de Barba, como, por exemplo, o Samurai / Gueixa, técnica advinda de Carlos Simioni, ator do grupo Lume, que participou dos Seminários de Pesquisa para Atores dirigidos por Iben Nagel Hasmussen, em dezembro de 1993 (BURNIER, 2001, p. 130-1). Nesta técnicas, os atores criam sua 'língua' a partir de certos princípios orientais (neste caso, as energias de pólos opostos complementares) para utilizá-la em cena. Podemos resumir essa técnica energeticamente como o samurai sendo um bloco, enquanto 
a gueixa seria a segmentação. As energias dessas duas figuras são opostas e complementares: o samurai reforça a força em si, enquanto a gueixa explora as possibilidades sutis de criação imagética. Barba chama esses "pólos complementares" de animus e anima.

Os conceitos de animus e anima (nos quais Barba se apoia advindos da psicologia analítica de Carl Gustav Jung) baseiam-se na duplicidade: anima é a energia suave; animus a vigorosa (forças opostas, para criar o equilíbrio). É o mesmo conceito das palavras balinesas keras e manis: keras é a força, o vigor; e manis a delicadeza. Há ainda tandava e lasya, que em hindu significam vigor e suavidade. Os nomes são diferentes, mas a ideia e os princípios, os mesmos, assim como o Yang e Yin chineses (GUERRA, 2015). Estes últimos são explicados pelo Tao (de origem chinesa, que significa caminho, ou passagem): o Yin é associado ao maleável, ao negativo, ao conservado, ao contrátil, ao intuitivo, ao sintético, ao feminino, ao misterioso; o Yang é a parte agressiva, expansiva, exigente, firme, positiva, objetiva, direta, racional, masculina. Na representação gráfica do símbolo chinês do Yin Yang, denominada tai chi (também nome de uma arte marcial, podendo ser traduzido como "grande energia"), temos um círculo dividido em duas partes, uma branca e outra preta. A parte branca contém uma pequena circunferência preta, e a parte preta uma pequena circunferência branca. Segundo Alice Curi (doutora em Artes Cênicas pela Universidade Federal da Bahia, atriz e professora), "Isso traduz uma particularidade da dinâmica: cada uma das faces extremas (pólos) carrega em si o germe da outra" (2008, p. 68).

E assim como o símbolo do Tao, entendo que o ocidente acaba por se "contaminar" do oriente, através de suas técnicas, características, aspectos e ideologias; bem como o Oriente se "contagia" do Ocidente em aspectos, formas e ideologias, tendo, ambos, em seu teatro, o germe do outro, num fluxo contínuo de movimento, entrelaçando-se e separando-se, cada um afim de gerar um mesmo produto, ainda que em formas distintas: Teatro.

\section{Referências}

ARTAUD, Antonin. O teatro e seu duplo. São Paulo: Martins Fontes, 1999.

AZEVEDO, Sônia Machado de. O papel do corpo no corpo do ator. São Paulo: Perspectiva, 2004.

BARBA, Eugenio \& SAVARESE, Nicola. A Arte secreta do ator: dicionário de Antropologia Teatral. São Paulo: Hucitec UNICAMP, 1995.

BURNIER, Luís Otávio. A arte de ator: da técnica à representação. Campinas, SP: Editora da UNICAMP, 2001.

BRECHT, Bertolt. Teatro Dialético. Rio de Janeiro: Civilização Brasileira, 1967.

CURI, Alice Stefânia. Espetáculo Traços: o Tao em cena. Cadernos do GIPE-CIT: Grupo Interdisciplinar de Pesquisa e Extensão em Contemporaneidade, Imaginário e Teatralidade No 19/Estudos em Movimento II: Corpo, Criação e Análise. Salvador: UFBA/PPGAC, 2008.

FERNANDES, Ciane. Por uma (est)ética fronteiriça: o trabalho de corpo na cena intercultural. In: ENCONTRO DE ESTUDOS MULTIDISCIPLINARES EM CULTURA, Salvador, 2008. IV ENECULT. Salvador: Faculdade de Comunicação/UFBa, 2008.

GASPAR VERDÚ, Maria Victoria. Influencia de las puestas en escena brechtinianas: El ejemplo de E. Boni. Valencia: Universitat de Valencia, 2003. Tese (Doutorado em Filologia Inglesa e Alemã), Universitat de Valencia, 2003.

GRANDE ROSALES, Maria Ángeles. Hacia un teatro global: cultura e identidad en el teatro contemporâneo. Teatro, Revista de Estudios Teatrales, Granada, 13/14, pp. 185-97, 1998-2001.

GROTOWSKI, Jerzy. Em busca de um teatro pobre. Rio de Janeiro: Civilização Brasileira, 1987.

El Performer. Máscara, México, Ano 3, nº 11-12, pp. 76-8, 1992-1993a. 
. Oriente/Occidente. Máscara, México, Ano 3, no 11-12, pp. 62-8, 1992-1993b.

GUERRA, Ariane. Diálogos Corporais: fronteiras entre o ator e a arte marcial. Curitiba: Editora Prismas, 2015.

OIDA, Yoshi. O Ator Invisível. São Paulo: Via Lettera, 2007.

QUILICI, Cassiano Sydow. Artaud e a nostalgia do rito. Revista Olhar, São Carlos/SP, Ano 3, nº 5-6, jan-dez 2001, pp. 1-4.

RAPOSO, Paulo. O caso Artaud e a (re)descoberta do oriente. Coimbra, 22 jul. 1997.

STANISLAVSKI, Constantin. A preparação do ator. Rio de Janeiro: Civilização Brasileira, 2005.

Recebido em 19/11/2015

Aprovado em 18/01/2016 